\title{
The efficiency of rehabilitation for self-service eating in institutionalized children aged 2-6 years with mental and motor retardation
}

\author{
DOI: https://doi.org/10.5114/pq.2018.73367
}

\author{
Dorota Wójtowicz, Julia Roshko, Agnieszka Ptak, Agnieszka Dębiec-Bąk, Anna Skrzek \\ University School of Physical Education in Wrocław, Wrocław, Poland
}

\section{Abstract}

Introduction. The purpose of the work is an evaluation of the efficiency of therapeutic programmes applied for manual skills in self-service eating, as well as for the motion range of chosen upper limb joints in children aged 2-6 years with mental retardation. Methods. The research was carried out among 2 groups of children, 12 members each. The methods used to evaluate the effects of the therapy included Sagittal Frontal Transverse Rotation (SFTR) as per International Standard Orthopaedic Measurements (ISOM) and Gunzburg's PPAC Inventory as adapted by Witkowski. The study presents the results of the therapy in a group run with the Vojta method and in a group run with other paediatric physiotherapy methods.

Results. The research results have shown no essential difference between the groups at the first measurement (before therapy), a statistically significant difference (an improvement in mobility and function) in the second test in both examined groups, and statistically significant results of comparing the first and second measurement for both methods, mostly in favour of the Vojta group.

Conclusions. The Vojta method therapy is more effective than the other therapeutic methods in improving both upper limbs motion and the self-service function of eating.

Key words: rehabilitation, children, eating function, self-sufficient, the Vojta method

\section{Introduction}

The mental development expressed in the child's motivation to carry out various tasks - made up of cognitive, intellectual, emotional, and social possibilities, especially in the first year of life, but also throughout the whole period of the child's development - depends on the motor development and visual and auditory functions, which are closely connected with performing self-service activities [1, 2]. Additionally, through the work of perception organs, the whole range of tactile, algetic, and kinaesthetic stimuli appear. They create a rich store of information, which, after proper selection and processing, becomes a driving force of all and any reactions $[3,4]$. The rule of a close relation between the mental and motor development indicates that a cognitive deficit will be coresponsible for a motor deficit and the other way round $[5,6]$.

The problem of performing self-service activities becomes complicated in children with intellectual disability, especially the severe and deep type. Severe intellectual disability is characterized by deficiencies in speech, thinking, perception, and concentration, as well as by inclinations to tell stories, confabulate, present aesthetic abnormalities, be controlled by drives, or behave in a way unfit for a situation. However, simple and uncomplicated life situations can be managed. Deep intellectual disability, in addition to frequent hearing and vision defects, as well as limb paralysis, is marked by a typical facial expression. Such people need assistance for self-service, have problems with understanding words and communicating, exhibit decreased pain sensitivity, and are irritable, apathetic, prone to destructive behaviour [6, 7].

Motor disability is any dysfunction of a human locomotive organ which may be a result of the following causes: damage or disorder of the nervous system function, genetically determined diseases, congenital defects, traumatic conditions, or others [8]. The disorders of the physical development may take on the form of retardation in acquiring physical skills meant for a given age, qualitative irregularities in performing functions, stereotypes, poorly diversified reactions to stimuli, persisting activity of reflex movements or lack of reflex movements at a time typical for their occurrence, and all and any dysfunctions of the sensor integration. Sensor integration dysfunctions are closely related to dysfunctions in other developmental spheres and lead to deficits in social functioning [9].

In children with physical development disorders, one can observe some specific behaviours whose existence should give rise to undertaking remedial, compensating, and corrective actions. The typical symptoms could be: physical awkwardness of the whole body, manual awkwardness, lateral dysfunction [8, 10]. Manual awkwardness is characterized by disorders in physical, visual, and auditory coordination. In such children, deficiencies in self-service can be present, e.g. with reference to eating, doing the shoelaces, doing up buttons, or other tasks. The movements are not precise enough, slow, often with the use of one hand only $[9,10]$.

The quality of life in children with a deficient psychomotor development is decreased by difficulties in performing self-service functions, including those concerning physiological needs, and disorders in carrying out cognitive functions. The lack of structural and biomechanical restrictions in the functioning of the limbs directly affects the self-service ability [11, 12].

A child with a damaged central nervous system (CNS) or a damage in the area of the brain - spinal cord - peripheral

Correspondence address: Julia Roshko, University School of Physical Education in Wrocław, al. I.J. Paderewskiego 35, 51-612 Wrocław, Poland, e-mail: julia.roshko@awf.wroc.pl

Citation: Wójtowicz D, Roshko J, Ptak A, Dębiec-Bąk A, Skrzek A. The efficiency of rehabilitation for self-service eating in institutionalized children aged 2-6 years with mental and motor retardation. Physiotherapy Quarterly. 2017;25(2):10-16; doi: https://doi.org/10.5114/pq.2018.73367. 
nerves - muscles shows signs of a disordered central nervous coordination. The cause of decreased manual activity is incorrect information coming from the damaged paths and brain structures to the muscles. The disturbed muscle tone can be manifested by asymmetry, incorrect body posture, and disorders in joint motion. Motion ranges in the upper limb joints condition the manual efficiency of a given limb [9].

The work has been devoted to institutionalized children who, owing to the environment in which they reside, manifest different kinds of behavioural dysfunctions. A number of studies have shown a considerable amount of mental disorders in children under treatment in closed intuitions. One can observe socially aggressive behaviour towards institutionalized children, along with an overdue care for their safety. Such social attitude results in limiting or totally blocking the development of retarded children [13, 14]. One should also point at a deficit or lack of prenatal care in the children under study, the effect of risk factors during pregnancy, and mental problems of the parents who have abandoned their child $[13,15]$.

As a result of his research, Robert Magnus came to the conclusion that every deliberate movement started from a specific body location and finished at a specific location. What is more, body posture accompanies motor activity like a shadow [16]. That became the foundation for Vojta's physiotherapeutic method, recognized as credible and effective in many countries [17].

Vojta's diagnostic and therapeutic concept makes it possible to early detect and treat disorders of physical development in children. The therapy affects the activation of a genetically coded pattern of reflex locomotion, consists in paving nerve paths - activating coordination fields in the CNS on the basis of temporal and spatial summation. The direct target is the correction of the quality of the motion pattern conditioning any functional improvement [17]. Initially, the correct muscle reaction to a stimulus can be observed only at the time of stimulation. It is only after motion fields of the cerebral cortex encode and remember the motion patterns paved that the new solutions get automatically utilized in the patient's spontaneous motor activity [18]. The development of the motion pattern takes place in definite directions: from the head towards the tail, and from the closer parts to the more distant ones. Disorders in the area formed by the head and the spine significantly affect the process of gradual muscle tone transmission in muscle chains to the parts of the body lying further away from the spine. The changes in the muscle tone transmission lead to the impairment or deactivation of the supporting and extensory function of the limbs, as well as of the manual functions of the upper limbs [19].

The purpose of the work is an evaluation of the efficiency of therapeutic programmes applied for manual skills in selfservice eating, as well as for the motion range of chosen upper limb joints in children aged 2-6 years with mental retardation.

\section{Subjects and methods}

\section{Participants}

The study included 24 children aged 2-6 years, residing from birth at the John Paul II Health Care Centre (HCC) at Jaszkotle, Poland. They presented intellectual and motor disabilities, diagnosed by a paediatric neurologist and indicated in an opinion by a psychological and pedagogical counselling centre; additionally, intense manual awkwardness was observed, manifested in dysfunctions in the development of self-service functions. All the examined children were found to be right-handed on the basis of observations of their everyday activities. The participants, randomly divided into 2 groups of 12, were rehabilitated for 3 months. One group was subjected to the Vojta method therapy, and the other one to therapy with other methods.

The Vojta group consisted of 6 boys and 6 girls. The con-

Table 1. Group allocation of the children depending on their diagnosis

\begin{tabular}{|c|c|c|c|}
\hline \multicolumn{2}{|c|}{ Vojta group } & \multicolumn{2}{c|}{ Control group } \\
\hline$n$ & Age (years) & $n$ & Age (years) \\
\hline
\end{tabular}

\begin{tabular}{|c|c|c|c|c|}
\hline \multicolumn{5}{|l|}{ Primary diagnosis } \\
\hline Infantile cerebral palsy & 2 & 5,6 & 4 & $3,4,6,6$ \\
\hline Retarded psychomotor development & 2 & 2,2 & 2 & 3,5 \\
\hline Down syndrome & 3 & $4,5,6$ & 2 & 6,6 \\
\hline Marfan syndrome & 2 & 3,4 & - & - \\
\hline West syndrome & - & - & 1 & 6 \\
\hline Cat-cry syndrome & 1 & 3 & - & - \\
\hline Foetal alcoholic syndrome & - & & 1 & 5 \\
\hline Autism, hearing loss & 1 & 5 & - & - \\
\hline Congenital hydrocephalus & 1 & 4 & - & - \\
\hline Congenital organic heart disease & - & - & 1 & 5 \\
\hline Prematurity, poor vision & - & - & 1 & 4 \\
\hline \multicolumn{5}{|l|}{ Age characteristics } \\
\hline Arithmetic mean (years) & \multicolumn{2}{|c|}{5} & \multicolumn{2}{|c|}{5} \\
\hline Standard deviation (years) & \multicolumn{2}{|c|}{1.4} & \multicolumn{2}{|c|}{1.3} \\
\hline
\end{tabular}


trol group included 10 boys and 2 girls; they underwent therapy with methods according to Bobath, Ayres (sensory integration), Sherborne, Castillo Morales. Table 1 presents the group allocation, with the consideration of the diagnosed conditions.

The examined group inclusion criteria were as follows:

- residing in an institution,

- considerable or deep mental retardation,

- motor retardation,

- right-handedness,

- age between 2 and 6 .

The following criteria for excluding were applied:

- light or moderate mental retardation,

- lack of progress in the institutionalized children's functional condition under regular rehabilitation for a year.

\section{Assessment methods}

On being qualified to the programme, all the children were examined twice: before the therapy was started and after 3 months of carrying out the pertinent therapeutic programmes. In both groups, we evaluated passive motion ranges in chosen upper right limb joints (humeral, ulnar, distal radioulnar), as well as the level of functioning of manual skills for the selfservice function of eating.

To evaluate the joint motion ranges, the Sagittal Frontal Transverse Rotation (SFTR) measuring and recording system was used (international SFTR method of measuring and recording joint motion), published by International Standard Orthopaedic Measurements (ISOM). The standards for joint motion are established by the American Academy of Orthopaedic Surgeons. To normalize the research, we assumed that the 'zero' value meant full extension of the joint [20, 21]. The range of joint motion was measured in degrees by means of a goniometer. The measurement was performed by two people: one of them stabilized the initial position, and the other made movements and took the measurement.

To evaluate manual skills, Gunzburg's PPAC Inventory as adapted by Witkowski was used, which, in addition to its basic purpose - social development assessment - can signal other abnormalities occurring along with the intellectual disability [22]. The whole inventory contains 130 tasks serving to estimate the child's potential. It is a multifunctional tool for diagnosis and therapy_monitoring. It contains evaluation criteria for serving oneself (eating, moving about, the toilet and washing, getting dressed), communicating, socializing, activities (agility, manual skills).

The children were evaluated in the eating function as a self-service element. On the PPAC diagram, mastering a task of the next higher difficulty level was marked. The comparison of the test results carried out before and after the therapy was indicated on one individual diagram by the same therapist, which made it possible to notice the changes in the child's skill level.

\section{Statistical methods}

The statistical analysis was performed with the Statistica 10.0 (StatSoft Inc., 2011) programme. After analysing the distribution of results with the Shapiro-Wilk test, a decision was made to use nonparametric methods. The Mann-Whitney $U$ test was applied for intergroup comparisons, and the Wilcoxon test for intragroup comparisons. The basic measures of descriptive statistics were calculated: the mean, median, quartile, standard deviation. In all statistical tests applied, test values and coefficients of $p \leq 0.05$ were considered statistically significant.

\section{Ethical approval}

The research related to human use has been complied with all the relevant national regulations and institutional policies, has followed the tenets of the Declaration of Helsinki, and has been approved by the authors' institutional review board (the Senate Commission for Scientific Research Ethics at the University School of Physical Education in Wroclaw, Poland).

\section{Informed consent}

Informed consent has been obtained from the legal guardians of all individuals included in this study.

\section{Results}

While analysing the results with the Mann-Whitney $U$ test, no statistically significant differences were found between the groups of children with reference to the motion ranges measurement with the SFTR method and to eating function evaluation with Gunzburg's PPAC carried out in examination 1 , before the rehabilitation. It can be accepted that the groups were homogeneous, both for joint motion and the eating function.

The analysis of the difference between examination 1 (before the rehabilitation) and examination 2 (after rehabilitation) in most tests revealed a statistically significant increase in motion ranges both in the Vojta and the control group. In the shoulder syndrome, mobility improvement was found for almost all movements tested. Except the S and $\mathrm{T}$ extension, all the motion ranges showed signs of a statistically significant increase. It was the same with the elbow joint and two distal radioulnar joints; as a result of cooperation in the $\mathrm{R}$ plane, the motion ranges increased, which except for extension and pronation presented a statistically significant change.

For the comparison of the effects of the rehabilitation process applied in the Vojta and the control group, the change in mobility was analysed in the two joints examined. The results between the two groups of children are shown in Table 2.

In Table 2, one can observe a measurably bigger improvement in the mobility of all tested movements between examinations 1 and 2 in the Vojta group as compared with the control group. In 5 of the 8 analysed comparisons, the results were statistically significant.

Then, the results of measuring the right elbow joint motion were analysed in the same way (in plane S) and two distal radioulnar joints as a result of cooperation in the right upper limb (in plane R) (Table 3). Also with these joints, one can observe a bigger improvement in the mobility of all tested movements between examinations 1 and 2 in the Vojta group than in the control group. In 3 of the 4 analysed comparisons, the results were statistically significant. Only the outcome of comparing the extension value in the elbow joint in plane $S$ showed no signs of improvement, regardless of the therapeutic method.

The analyses carried out unequivocally showed that there was a significant difference in the therapy effects, with the Vojta group achieving better results. The test results prove the efficiency of the therapeutic activities undertaken in both groups of subjects examined for the period of 3 months. Statistically significantly higher difference values between measurements 1 and 2 were achieved in the group rehabilitated with the Vojta method. 
Table 2. Analysis of the difference in motion range of the right shoulder girdle in examinations 1 and 2 between the Vojta and the control group

\begin{tabular}{|c|c|c|c|c|c|c|c|c|}
\hline Group & Plane & $\begin{array}{l}\text { Measured difference between } \\
\text { examinations } 1 \text { and } 2\end{array}$ & Mean & Median & $\begin{array}{l}\text { Lower } \\
\text { quartile }\end{array}$ & $\begin{array}{l}\text { Upper } \\
\text { quartile }\end{array}$ & $S D$ & $p$ \\
\hline Vojta & S & extension & 15.8 & 20 & 0 & 30 & 15.1 & \multirow{2}{*}{0.1749} \\
\hline Control & $S$ & extension & 6.7 & 5 & 0 & 10 & 7.8 & \\
\hline Vojta & S & bend & 48.8 & 50 & 35 & 67.5 & 25.4 & \multirow{2}{*}{$0.0015^{\star}$} \\
\hline Control & S & bend & 14.2 & 10 & 10 & 15 & 10.8 & \\
\hline Vojta & $\mathrm{F}$ & abduction & 55.8 & 50 & 30 & 85 & 30.9 & \multirow{2}{*}{$0.0015^{\star}$} \\
\hline Control & $\mathrm{F}$ & abduction & 16.3 & 15 & 10 & 20 & 12.3 & \\
\hline Vojta & $\mathrm{F}$ & adduction & 0.0 & 0 & 0 & 0 & 0.0 & \multirow{2}{*}{0.9770} \\
\hline Control & $\mathrm{F}$ & adduction & 0.0 & 0 & 0 & 0 & 0.0 & \\
\hline Vojta & $\mathrm{T}$ & extension & 8.3 & 10 & 0 & 10 & 8.3 & \multirow{2}{*}{0.0833} \\
\hline Control & $\mathrm{T}$ & extension & 5.4 & 0 & 0 & 2.5 & 14.4 & \\
\hline Vojta & $\mathrm{T}$ & bend & 34.2 & 25 & 12.5 & 55 & 24.8 & \multirow{2}{*}{$0.0153^{*}$} \\
\hline Control & $\mathrm{T}$ & bend & 12.1 & 10 & 7.5 & 20 & 6.9 & \\
\hline Vojta & $\mathrm{R}$ & external rotation & 38.8 & 35 & 20 & 60 & 25.9 & \multirow{2}{*}{$0.0111^{\star}$} \\
\hline Control & $\mathrm{R}$ & external rotation & 14.2 & 10 & 10 & 20 & 10.0 & \\
\hline Vojta & $\mathrm{R}$ & internal rotation & 25.4 & 15 & 10 & 40 & 24.6 & \multirow{2}{*}{$0.0226^{*}$} \\
\hline Control & $\mathrm{R}$ & internal rotation & 5.8 & 5 & 0 & 10 & 5.1 & \\
\hline
\end{tabular}

* Statistically significant results $(p \leq 0.05)$

Table 3. Analysis of the difference in motion range of the right elbow joint and right distal radioulnar joints in examinations 1 and 2 between the Vojta and the control group

\begin{tabular}{|c|c|c|c|c|c|c|c|c|}
\hline Group & Plane & $\begin{array}{l}\text { Measured difference between } \\
\text { examinations } 1 \text { and } 2\end{array}$ & Mean & Median & $\begin{array}{l}\text { Lower quar- } \\
\text { tile }\end{array}$ & $\begin{array}{c}\text { Upper quar- } \\
\text { tile }\end{array}$ & $S D$ & $p$ \\
\hline Vojta & $S$ & extension & 0.0 & 0 & 0 & 0 & 0.0 & \multirow{2}{*}{0.9770} \\
\hline Control & $S$ & extension & 0.0 & 0 & 0 & 0 & 0.0 & \\
\hline Vojta & $S$ & bend & 36.7 & 30 & 10 & 60 & 31.4 & \multirow{2}{*}{$0.0051^{*}$} \\
\hline Control & $S$ & bend & 8.3 & 10 & 5 & 10 & 5.4 & \\
\hline Vojta & $\mathrm{R}$ & supination & 30.4 & 27.5 & 15 & 50 & 19.6 & \multirow{2}{*}{$0.0067^{*}$} \\
\hline Control & $\mathrm{R}$ & supination & 9.2 & 10 & 5 & 10 & 6.7 & \\
\hline Vojta & $\mathrm{R}$ & pronation & 21.3 & 10 & 10 & 35 & 18.1 & \multirow{2}{*}{$0.0179^{*}$} \\
\hline Control & $\mathrm{R}$ & pronation & 5.8 & 10 & 0 & 10 & 5.1 & \\
\hline
\end{tabular}

* Statistically significant results $(p \leq 0.05)$

The analysis of the results for the eating function in the PPAC test has been presented graphically. Included is information about the test results in measurement 1 (Figure 1) and in measurement 2 (Figure 2), as well as about the difference between measurements 1 and 2 (Figure 3 ) in both groups of the children examined for the eating function. In examination 1, the Vojta group showed higher results than the control group, though the difference is not statistically significant $(p=0.0783)$.

While evaluating children for the eating function in examination 2, after the therapy (Figure 2), one could observe a significantly higher $(p=0.0086)$ advancement level of the function in the Vojta group, which testifies to better therapeutic effects.
The tests carried out with the Gunzburg's PPAC Inventory present statistically significant differences between the measurements in each programme of the therapy. Figure 3 shows the results of the differences between the assessment before and after the therapy concerning the eating function in both examined groups. The diagram shows that the Vojta group manifested a bigger improvement in the eating function than the control group. The difference between the improvement in the Vojta and the control group was statistically significant $(p=0.0153)$. 


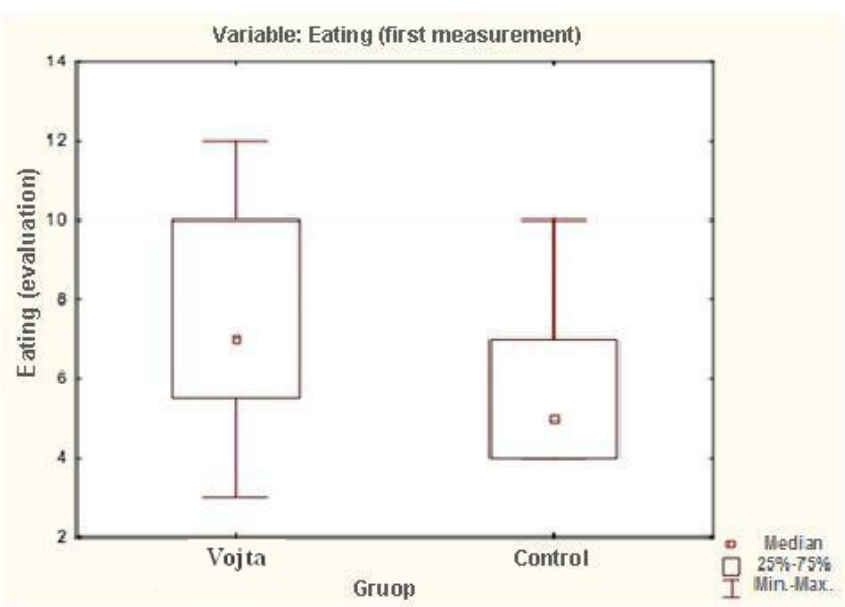

Figure 1. Evaluation of the eating function in examination 1 for the Vojta and control groups

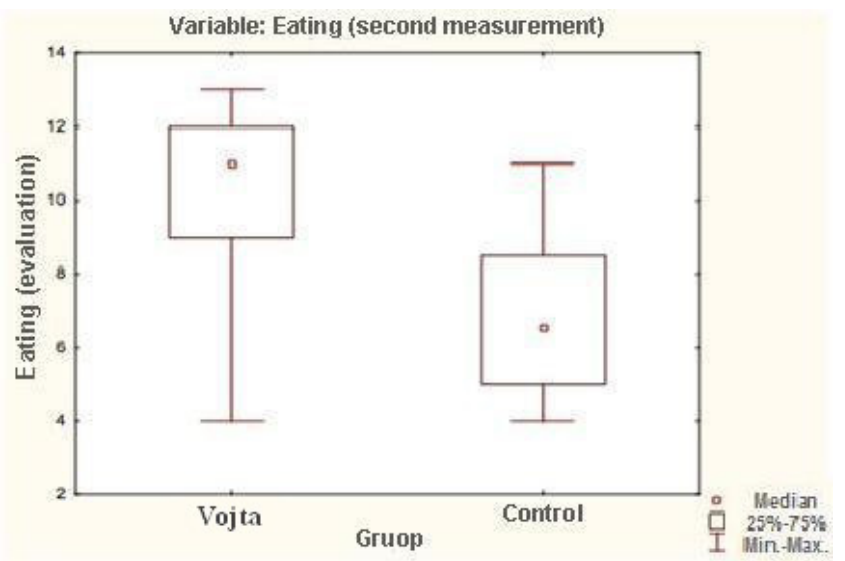

Figure 2. Evaluation of the eating function in examination $2 f$ or the Vojta and control groups

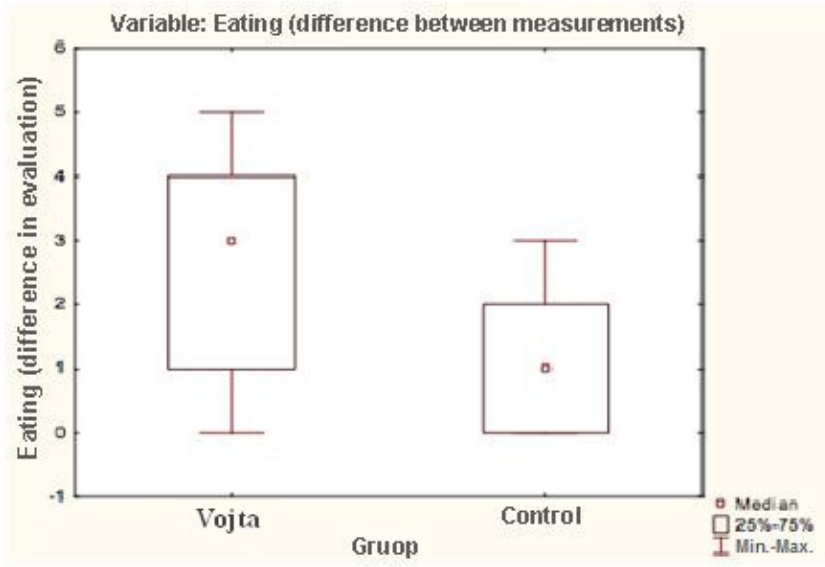

Figure 3. Differences between examinations 1 and 2 for the eating function between the Vojta and control groups

\section{Discussion}

In a 3-month therapy plan, the Vojta method turns out more effective than the other physiotherapy methods in paediatrics combined in a therapeutic programme. Test results prove that even a 3-month therapeutic programme brings the effects expected in the form of increased joint motion, leading to an improvement in life quality, higher level of self-service in the eating function, as well as an increased chance of accommodation to the society and active participation in it.
A review of research works concerning the efficiency of neurokinesiological therapy with reflex locomotion reveals a favourable therapeutic effect on the psychomotor development, similarly supported with test results.

While examining the efficiency of the Vojta method therapy, Czenczek-Lewandowska et al. [23] observed two groups of children rehabilitated with the Vojta method, one of whom was subjected to the therapy for less than 6 months, and the other one for less than 12 months. They proved that the Vojta method therapy was effective and brought results while treating infants whose rehabilitation was started before the $6^{\text {th }}$ month of life. The authors point to a connection between the therapy efficiency, its duration, and the age at which it is started. What seems to be a restraint of the studies is the lack of a comparative group not applying the Vojta method therapy. Also, the studies do not present the initial condition of the examined children, before the rehabilitation process.

Carrying out studies in a group of 64 infants subjected to neurodevelopmental therapy with the Vojta and Bobath methods, Pyda-Dulewicz [24] proved a highly essential relation between the therapy in the Vojta group and an improvement in symmetry, potential for isolated movements in the cervical section of the spine, and also an improvement in the sucking function. The fact of group inhomogeneity and the way the children were selected remain doubtful.

Wójtowicz and Dołyk [25] examined the effect of the Vojta method therapy in a group of 40 infants with central nerve coordination disorder (CNCD) and a limited abduction movement in the hip joints against a group of healthy infants. They manifested significant changes in the motion ranges of hip joints as a result of a 6-month Vojta therapy. While continuing studies concerning the given field, it would be worthwhile to expand the methodology to include image examination, e.g. scanning hip joints, which seems to be a precise examination method, at the same time registering the therapeutic progress.

Examining the motor development of children born after the $32^{\text {nd }}$ week of gestation, stimulated as per the recommendations and principles of the Vojta method, Dytrych [17] noted an improvement in the motor development in $61 \%$ of the patients, with the rest of the children not achieving the correct motor development. The frequency of the therapy was selected individually for each child. Further prospective studies need to be continued with a view to evaluating the efficiency of the Vojta method. However, it is worth introducing therapy homogeneity in terms of duration and the number of therapeutic sessions in order to evaluate its effectiveness.

Carrying out perennial studies on the effect of the Vojta diagnosis and therapy, Sadowska [26] believes that the Vojta method diagnostics precisely determines the state of maturity of the CNS, as well as the disturbance level in its operation at the individual development stages. On the basis of studies and observation, the author proves the efficiency of the therapy in children with CNCD, but still she is convinced that the most essential factors include the age of the child at which the therapy starts and the degree of the CNS function disturbance.

Despite a large number of studies proving the efficiency of the Vojta method therapy, some authors, therapists, doctors, and parents perceive the method to be controversial, thus pointing to the need for more studies [27].

The efficiency of the therapy with the Vojta method is also confirmed in the works by Banaszek [28] and Surowińska [29].

While studying the efficiency of rehabilitation methods, including the Vojta method, in children with myelomeningo- 
cele and delayed crawling and sitting function, OkurowskaZawada et al. [30] maintain that none of the rehabilitation methods conditioned a direct rehabilitation effect, despite influencing the psychomotor development and the occurrence of correct motor patterns. The degree of locomotion achieved was in turn directly dependent on the degree of the spinal cord damage. However, the paper did not present any information about the programmes or therapeutic methods used earlier in the examined patients.

In her work, Ptak [31] used the PPAC Inventory to evaluate the development of social competence after applying occupational therapy in intellectually disabled children staying at a health care centre. Among the social competences measured by the inventory is the ability to eat, whose level changed in a statistically significant way. The study proved that even 3 months of the therapy brought specific effects in the form of improving motion ranges, as well as the eating function in intellectually disabled children. However, the time scale allowed for the therapy included 2 years of training. A limitation of the research material in the study was the number of people examined; since what was considered was an individual case, it is not possible to transfer the achieved result to populations.

Michalska et al. [32] evaluated changes in the functioning of two siblings with a clinical diagnosis of mucopolysaccharidosis type A using Gunzburg's PPAC. The results consisted in a short-lived improvement in the functioning of the children observed for self-service, communication, and activities. In children with a progressively decreasing level of functioning, a need for a functional evaluation is stressed in order to undertake an individual therapeutic procedure and life quality improvement.

In studies on life quality in children with myelomeningocele, Schoenmakers et al. [33] marked out self-dependence for mobility as the most important factor determining functional independence. The authors demonstrated that this function, along with muscle strength and mental efficiency, generated life comfort for disabled children.

In a study on the effect of the Vojta method therapy and another neurodevelopmental therapy in children with asymmetry, Jung et al. [34] presented conclusions in which both therapeutic methods were evaluated as effective, with the Vojta method bringing a better therapeutic result. Postural asymmetry was diagnosed in a paediatric examination. It seems sensible to expand studies to include image diagnostics in order to raise the weight of methodological quality. A good proposal seems to be a PodoBaby computer podoscope.

There are not enough scientific reports on similar subjects, though. Still, they are extremely important for the diagnostic process and planning both integrated and individual therapeutic programmes.

While implementing the diagnostic and therapeutic plan analysed in the study, it was found that the Vojta method, used to improve manual skills for the self-service function, was more effective than the other methods of paediatric physiotherapy combined in a therapeutic programme. An improvement in the upper limb motion means qualitative changes in the motion pattern as a result of the Vojta method. Despite the intellectual deficit in the children examined, the changes significantly improved the manual functions here, eating. This can probably be explained by the chain distribution of muscle tone in the individual parts of the body. The correct development of postural tension in the ontogenesis of the first year of life points to a relationship and changes in the axial tension in the trunk and head area in terms of peripheral tension in the upper and lower limbs.
The changes are reflected in the value of the individual motion ranges, and these, in turn, condition function improvement. In children with complex disability, self-service is extremely important, allowing them to become independent for the most basic, but also most significant everyday life activities. The study presents results concerning joint motion and the eating function for self-service skills. What is more, motor activity in the form of controlling one's own body was improved, which contributes to attention concentration. However, it is worth elaborating on the subject taking into account other significant factors affecting the life quality and social functioning of disabled children.

\section{Conclusions}

1. All the studied therapeutic systems are effective in improving the eating function.

2. The Vojta method therapy is a more effective method in improving the eating function.

3. The Vojta method and the system of using many therapeutic methods excluding the Vojta therapy are effective in improving mobility in upper limb joints.

4. The Vojta method therapy is more effective than the other therapeutic methods in improving mobility in upper limbs.

\section{Disclosure statement}

No author has any financial interest or received any financial benefit from this research.

\section{Conflict of interest}

The authors state no conflict of interest.

\section{References}

1. Cytowska B. Conductive education as a method of developing self-reliance and autonomy of children and young people with profound intellectual disabilities [in Polish]. Interdyscyplinarne Konteksty Pedagogiki Specjalnej. 2016;12:61-83.

2. Pueschel SM. For a better future. Down syndrome. A guide for parents and carers [in Polish]. Zakrzewo: Replika; 2009.

3. Madejewska M, Choińska AM, Gieysztor EZ, Trafalska A. Neuromotorical assessment of children aged 4-7 from the Kamienna Góra district based on Sally Goddard tests [in Polish]. Piel Zdr Publ. 2016;6(3):179-186; doi: 10.17219/pzp/64033.

4. Gieysztor EZ, Choińska AM., Paprocka-Borowicz M. Persistence of primitive reflexes and associated motor problems in healthy preschool children. Arch Med Sci. 2018;14(1):167-173; doi: 10.5114/aoms.2016.60503.

5. Borkowska M. Motor disability in children [in Polish]. In: Loska M, Myślińska D (eds.), A student with mobility impairment in a public school [in Polish]. Warszawa: Ministerstwo Edukacji Narodowej i Sportu; 2005; 7-11.

6. Escobar-Koch T, Banker J, Crow DS, Cullis J, Ringwood S, Smith G, et al. Service users' views of eating disorder services: an international comparison. Int J Eat Disord. 2010;43(6):549-559; doi: 10.1002/eat.20741.

7. Krupa T, Fossey E, Anthony WA, Brown C, Pitts DB. Doing daily life: how occupational therapy can inform psychiatric rehabilitation practice. Psychiatr Rehabil J. 2009; 32(3):155-161; doi: 10.2975/32.3.2009.155.161.

8. Borkowska M. Child with physical disability [in Polish]. Warszawa: PZWL; 2012. 
9. Maas VF. Learning by the senses. Introduction to the theory of sensory integration [in Polish]. Warszawa: WSiP; 2005.

10. Kowalewski I. Motor development disorders in children before the start of school [in Polish]. Rocznik Komisji Nauk Pedagogicznych. 2014;67:15-30.

11. Rzeźnicka-Krupa J. Communication. Education. Society [in Polish]. Kraków: Oficyna Wydawnicza Impuls; 2007.

12. Lewis A, Parsons S, Robertson C, Feiler A, Tarleton B, Watson $D$, et al. Participation in research: reference, or advisory, groups involving disabled people: reflections from three contrasting research projects. $\mathrm{Br} J$ Spec Educ. 2008;35(2):78-84;doi:10.1111/j.1467-8578.2008.00376.x.

13. Hermenau K, Hecker T, Ruf M, Schauer E, Elbert T, Schauer M. Childhood adversity, mental ill-health and aggressive behavior in an African orphanage: changes in response to trauma-focused therapy and the implementation of a new instructional system. Child Adolesc Psychiatry Ment Health. 2011;5:29; doi: 10.1186/17532000-5-29.

14. Højberg AL, Steffensen BF. Developing and maintaining of user-defined personal competencies among young adults with congenital physical disability. Dev Neurorehabil. 2008;11(3):225-235; doi:10.1080/17518420801956649.

15. Wiik KL, Loman MM, Van Ryzin MJ, Armstrong JF, Essex MJ, Pollak SD, et al. Behavioral and emotional symptoms of post-institutionalized children in middle childhood. J Child Psychol Psychiatry. 2011;52(1):56-63; doi: 10.1111/j.1469-7610.2010.02294.x.

16. Aspects of diagnosis with the Vojta method [in Polish]. Available from: https://www.vojta.com/pl/zasada-vojty/ diagnostyka-vojty/aspekty.

17. Dytrych G. Analysis of motor development of premature born children with low body weight rehabilitated with the Vojta method [in Polish]. Neurol Dziec. 2009; 18(35):41-48.

18. Vojta V. The cerebral movement disorders in infancy: early diagnosis and early therapy [in German], ${ }^{\text {th }}$ ed. Stuttgart, New York: Georg Thieme Verlag; 2008.

19. Vojta V, Peters A. Introduction to reflex motion [in Polish]. In: Vojta V, Peters A. The Vojta method: muscular games in reflex motion and movement ontogenesis [in Polish]. Warszawa: Fundacja Promyk Słońca; 2006; 27-53.

20. Kuliński W, Zeman K. Physiotherapy in paediatrics [in Polish]. Warszawa: PZWL; 2012.

21. Dormans JP. Musculoskeletal examination [in Polish]. In: Dormans JP. Pediatric orthopedics [in Polish]. Wrocław: Elsevier Urban \& Partner; 2009; 16-34.

22. Witkowski T. PPAC Gunzburg inventory handbook for assessing progress in the social development of the mentally retarded [in Polish]. Warszawa: COMPWZ MEN; 1988.

23. Czenczek-Lewandowska E, Przygoda Ł, Szklarska-Witek I, Bejster A, Sadowska L. Changes in motor development in infants participating in rehabilitation based on Vojta method. Med Rev. 2016;14(3):266-277; doi: 10.15584/medrev.2016.3.2.

24. Pyda-Dulewicz A. The influence of Vojta reflex turning phase 1 on cervical range of motion in infants [in Polish]. Ann Acad Med Siles. 2015;69:111-117; doi: 10.18794/ aams $/ 34875$.

25. Wójtowicz D, Dołyk B. Influence of Vojta therapy on hip mobility in infants with motor disorders of central origin [in Polish]. Fizjoterapia. 2006;14(3):40-49.
26. Sadowska L. Neurophysiological methods of improving children with developmental disorders [in Polish]. Wrocław: Wydawnictwo AWF; 2004.

27. Dytrych G. Controversies around the Vojta method: a therapist's look [in Polish]. Neurol Dziec. 2008;17(33):59-62.

28. Banaszek G. The Vojta method as early neurodevelopmental diagnostics and a therapeutic concept [in Polish]. Przegl Lek. 2010;67(1):67-76.

29. Surowińska J. Neurokinesiological diagnosis according to Vojta [in Polish]. Prakt Fizjoter Rehabil. 2010;6:16-23.

30. Okurowska-Zawada B, Sobaniec W, Kułak W, Sendrowski K, Otapowicz D. Analysis of motor development of children with myelomeningocele and methods of rehabilitation [in Polish]. Neurol Dziec. 2008;17(33), 31-38.

31. Ptak $A$. The course of the process of acquiring social competence in the field of self-care under the influence of occupational therapy in children living in a care and treatment facility. In: Sekułowicz MJ (ed.), Occupational therapy: an international perspective [in Polish]. Kraków: AWF; 2012; 187-203.

32. Michalska A, Nawrocka M, Znój D. The progressive reduction of functioning in the course of mucopolysaccharidosis type IIIA - longitudinal study of two siblings. Pediatr Endocrinol Diabetes Metab. 2013;19(4):125-131.

33. Schoenmakers MA, Uiterwaal CS, Gulmans VA, Gooskens RH, Helders PJ. Determinants of functional independence and quality of life in children with spina bifida. Clin Rehabil. 2005;19(6):677-685; doi: 10.1191/02692 15505 cr865oa.

34. Jung MW, Landenberger M, Jung T, Lindenthal T, Philippi H. Vojta therapy and neurodevelopmental treatment in children with infantile postural asymmetry: a randomised controlled trial. J Phys Ther Sci. 2017;29(2):301-306; doi: 10.1589/.jpts.29.301. 